\title{
DEGRADATION OF ACRYLIC ACID-GRAFTED CELLULOSE IN AQUEOUS MEDIUM WITH RADICAL INITIATORS
}

\author{
AIDA NEIRA ${ }^{1}$, MIGUEL ZARRAGA² AND ROSA CATALAN ${ }^{2}$ \\ ${ }^{I}$ Facultad de Ciencias, Universidad del Bío-Bío, Avda. Collao 1202, Concepción, Chile. \\ ${ }^{2}$ Facultad de Ciencias Quimicas, Universidad de Concepción, Casilla 160-C, Concepción, Chile
}

(Received: 2 November 2006 - Accepted: 21 March 2007)

\begin{abstract}
The chemical modification of cellulose by grafting reaction with Acrylic Acid (AA) considering different reaction factors was investigated. Natural polymers such as Santa Fe Cellulose, Microcrystalline Cellulose (Avicell) and Secondary Pulp were studied as substrates. pH effect; Ce (IV), Mn(VII) and Fenton as initiators; time and temperature polymerization were investigated. Grafting reachs a maximum, $90 \%$ graft, at $\mathrm{pH} 7$. A medium to weak $\mathrm{C}=\mathrm{O}$ band at $1715 \mathrm{~cm}^{-1}$ for carboxylic group in FTIR spectroscopy is presented. Santa Fe and Avicel cellulose grafted whith AA at 17 hours are degraded. Secondary pulp with Fenton at $50-60$ and $70{ }^{\circ} \mathrm{C}$ at 17 hours are degraded too. The degradation of polymers at long reaction times at 17 hours and $70^{\circ} \mathrm{C}$ were analized by FTIR spectroscopy and electronic microscopy analysis (SEM).
\end{abstract}

Keywords: Degradation temperature, Radical polymetization, characterization.

\section{INTRODUCTION}

The chemical modification by grafting copolimerization of synthetic or natural polymers, pulp, and paper, to obtain new materials is of increasing interest in macromolecular science and technology [1-5]. It is an important technique to modify polymeric products with hydrophilic and hydrophobic monomers [6,7]. The graft copolimerization modificates the chemical and physical properties of polymers. Polymer degradation gives information about the product natures of polymer chemical oxidation [8-11]. Graft polymerization of insaturated monomers (vinyl monomers) onto cellulose, in water media, is one of the universal, effective and accessible methods of radical polymerization. A large quantity of articles about graft polymerization, properties and process kinetics are reviewed $[5,12,13]$. It is necessary to take into consideration metal ion interactions with monomers and water in the formation of corresponding radicals. Metal ions of variable valence such as $\mathrm{Ce}$ (IV), $\mathrm{Fe}(\mathrm{II}), \mathrm{Mn}(\mathrm{VII}), \mathrm{Mn}(\mathrm{III}), \mathrm{V}(\mathrm{V}), \mathrm{Cr}(\mathrm{VI})$ and $\mathrm{Co}(\mathrm{III})$ are investigated in the formation of free radicals. $[14,15]$. The ability to use Fenton-based systems in dark or light irradiation has been a topic of interest in the field of advanced oxidation technologies involving degradation of polulants. It has been found that illumination of the $\mathrm{Fe}^{2+}-\mathrm{Fe}^{3+}-\mathrm{H}_{2} \mathrm{O}_{2}$ system increases the degradation rate of many organic substances [16,17]. Photo -Fenton catalityc of an azo - dye, Orange II, has been studied. Prephotocatalytic degradation leads to the observed oxidation of three compounds considered[18].

To investigate cellulose structure and the mechanism of reaction and degradation, is useful improved_spectroscopy and Microscopy analysis. Rowan et al, have deal with the application of IR method to various aspects of cellulose chemistry [19]. Liang et al [20]considered the relationship between the IR spectra of polymers and those of the monomers of which they are composed. H.G.Higgins et al [21]reports effect of crystallinity on the spectra of sugars, cellulose, influence of hydroxymethyl side chain on cellulose, deuterated cellulose I and II, glucose pentaacetate, effect of substitution in hydroxyl groups and other experiences. An actual graft application to copolimerization of herbicide - containing acrylic monomers conduces to introduce changes in the polymer structure and therefore the ability to control the herbicide - polymer ratio. The free radical copolimerization of AA with a vinyl ester derived of 2,4- dichlorophenoxy acetic acid $(2,4-\mathrm{D})$, a growth regulator herbicidy is reported [22] Graft copolymerization continues as an important method to obtain polymers of Acrylic Acid onto Polypropylene(PP). The water conservation, water absorption rate and $\mathrm{K}^{+}$exchange capacity were determined on the grafted PP blown nonwovens with a 3- dimentional network. This structure is fabricated by ultrafine fibers, wich gives them small pore, brighporosity, good filtrations and absorption properties [23].

Some oxidants have been successfully used to initiate graft copolimerization onto cellulosic substrate. Toyo Rayon Co [24] carried out graft copolimerization of acrylonitrile onto pre- treated rayon fibers using $\mathrm{KMnO}_{4}-\mathrm{H}_{2} \mathrm{SO}_{4}$ system as a catalyst. El-Rafie et al [25] used dimethyl anilina- Copper Sulphate $\left(\mathrm{Cu}^{2+}\right)$ as an initiator system to graft polimerize methyl metacrylate onto viscose stable fibers. Acidic Potassium Permanganate is an efficient initiator for grafting the acrylic monomers onto starch, linters and dissolved wood pulp. Polymerization at room temperature gave copolymers with $98 \%$ grafting efficiency ( $2 \%$ homopolymer ) [26]. If the polimerization medium is sufficiently acidic to dissolve the Manganese dioxide produced by the interaction of the monomer with the permanganate, polymerization can be affected. In adition to suitable reducing agents, especially organic acids, such as, $\mathrm{H}_{2} \mathrm{C}_{2} \mathrm{O}_{4}$ oxalic acid, permanganate provides efficient redox systems. Some such pairs are : $\mathrm{KMnO}_{4}$ / tartaric acid [27] , $\mathrm{KMnO}_{4} /$ malic acid [28], $\mathrm{KMnO}_{4} / \mathrm{H}_{2} \mathrm{C}_{2} \mathrm{O}_{4}$ [29], $\mathrm{KMnO}_{4}$ /glyceric acid [30], $\mathrm{Mn}^{3+} /$ ethoxyaceticacid redox systems [31] were studied in the aqueous polymerization of AAm

Ceric ions are capable of forming radicals at the backbone of the cellulose in the presence of acid [32]. The grafting of monomers mixture on cellulose is carried out in aqueous medium. Thus, ethylmethacrylate with antimicrobial properties is grafting onto cellulose with Ceric ammonium nitrate, CAN, in combination with Acrylonitrile with an alternate arrangement of monomer blocks in the grafted copolymer chain [33]. The Ceric ion method has been used to graft Acrylic acid onto cellulose with a minimum amount of homopolymer. Mc Dowall, Gupta and Stannett [34] have reported yield up to $60 \%$ and less than 5\% homopolymer. Vitta, Stahel and Stannett[35] prepared a solution dissolving a known amount of CAN in $0.1 \mathrm{~N}$ nitric acid and mixing with deionised water. Copper powder was added to inhibit homopolymer formation.

Continuing with our grafting copolymerization studies [36], this paper reports grafting copolymerization and oxidative degradation by radical initiators of cellulose pulp, Santa Fe cellulose and microcrystalline cellulose with acrylic acid. $\mathrm{Fe}(\mathrm{II}) / \mathrm{H}_{2} \mathrm{O}_{2}, \mathrm{Ce}(\mathrm{IV}), \mathrm{Mn}$ (VII) are using as radical initiators at differents pHs, reaction time and reaction temperatures. $\mathrm{Mn}$ (II) and $\mathrm{Cu}(\mathrm{II})$ salts are using as catalyst systems.

\section{EXPERIMENTAL}

Preparation of cellulose and acrylic acid solutions to graft: Acrylic acid was obtained from the Merck and purified by distilling twice under vacuum in the presence of copper to prevent polymerization. The reaction medium was first degassed by passing nitrogen through the aqueous solution for at least 30 minutes. An exact mass of cellulose fiber (secondary pulp, Santa Fe cellulose or Avicel) is agitated in the corresponding aqueous initiator: Fenton, $\mathrm{Mn}(\mathrm{VII})$ or $\mathrm{Ce}$ (IV) solutions. Nitrogen gas continued to be bubbled through the medium during the wole reaction period. After the reaction time was completed, the grafted cellulose product was removed and washed thoroughly to remove the soluble contents. Finally, the grafted polymer was extracted with the solvent appropriate for the homopolymer, methanol for polyacrylic acid. Twenty-four hours was found to lead to constant weights.

Preparation of secondary cellulose reacting with Fenton. The method and the reaction system is the same described for grafting cellulose with Acrylic acid and Fenton reagent.

Infrared Spectroscopy. Infrared spectra was obtained by a Nicolet Magna 550 . The samples powdered were prepared in $\mathrm{KBr}$ pellets.

Electron Microscopy. The morphology of the polymers was studied with a SEM instrument, an AUTOSCAN U-1. The samples were treated with gold previously. 


\section{RESULTS AND DISCUSSION}

The chemical modification of the grafted cellulose is affected by factors such as: $\mathrm{Fe}^{2+}$ concentration, $\mathrm{H}_{2} \mathrm{O}_{2}$ concentration, cellulose-comonomer relation, $\mathrm{pH}$, temperature, and polymerization time. In Figures 1 and 2, it can been observed that the graft percentage for acrylic acid in the cellulose fiber increased with increased $\mathrm{pH}$, reaching a maximum at $\mathrm{pH}$ 7. An abrupt diminishment of this percentage is produced at higher pHs. Basically, this can be due to an increase of the charge density on the carbonyl as a result of acid deprotonation, the reactivity of the vinyl group is diminished. At a higher iron concentration, a significant graft increase also exists.

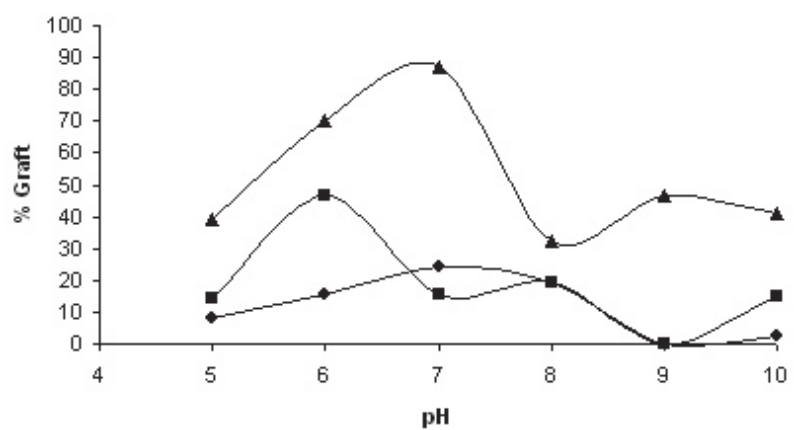

Figure $1: \mathrm{pH}$ effect on the reaction grafting Acrylic Acid on cellulose $\boldsymbol{\Delta}\left[\mathrm{Fe}^{2+}\right]=10 \mathrm{mM} ; \mathrm{H}_{2} \mathrm{O}_{2}=20 \mathrm{mM} ; \mathrm{T}^{\circ} \mathrm{C}=60 ;$ time $=2$ hours; Cel: $\mathrm{AA}=1: 2$

- $\left[\mathrm{Fe}^{2+}\right]=20 \mathrm{mM} ; \mathrm{H}_{2} \mathrm{O}_{2}=20 \mathrm{mM} ; \mathrm{T}^{\circ} \mathrm{C}=60$; time $=2$ hours; Cel: $\mathrm{AA}=1: 2$

- $\left[\mathrm{Fe}^{2+}\right]=10 \mathrm{mM} ; \mathrm{H}_{2} \mathrm{O}_{2}=20 \mathrm{mM} ; \mathrm{T}^{\circ} \mathrm{C}=60$; time $=2$ hours; Cel: $\mathrm{AA}=1: 3$

The capacity of chitosan to absorb iron (III) ion from an Jectofer, an Iron (III) sorbitol - citric acid complex solution, was investigated. This, to mimic the composition of excess iron (III) as may be found in biological systems [37].

The amount of iron (III) adsorbed onto chitosan increases with the contact time during 3 hours at $37^{\circ} \mathrm{C}$. Higher $\mathrm{pH}$ values in the range 2 to 7 , also resulted in an increase in iron(III). Chitosan samples were analized by FTIR spectroscopy before and after contact with the Jectofer solution. The amount of iron(III) adsorbed increases in time, reaching equilibrium within 3 hours.

It can been observed in Figure 1a, an graft increase with $\mathrm{pH}$ values, reaching a maximum at $\mathrm{pH}$ 7. The $\mathrm{C}=\mathrm{O}$ group increases in intensity as the $\mathrm{pH}$ increases. Figure 2 presents grafted cellulose FTIR spectras. They inclue the typical $\mathrm{C}=\mathrm{O}$ group band at $1718 \mathrm{~cm}^{-1}$. This band increases in intensity as the $\mathrm{pH}$ increases, reaching a maximum at $\mathrm{pH} 7$.

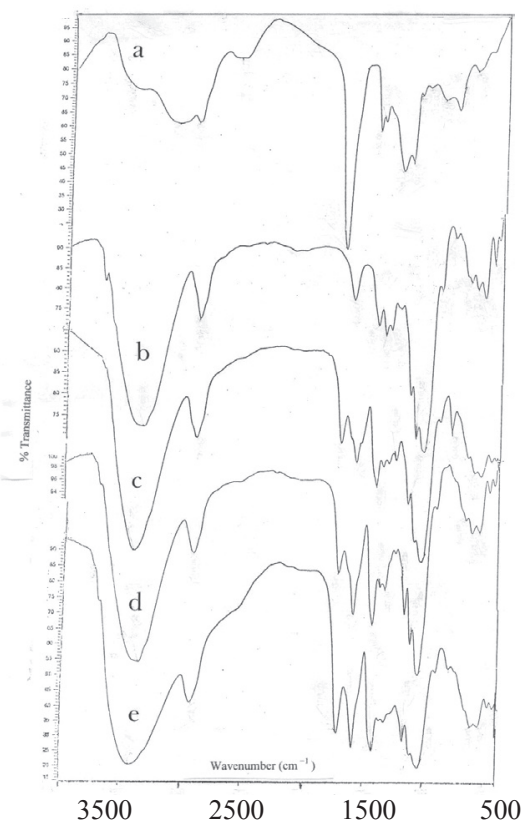
$\mathrm{pH}$.

Figure 2: FTIR spectrum for Polyacrylic Acid and Cel-g-AA at different
a) Polyacrylic Acid (PAA)
b) $\quad$ Cel-g-AA, $\mathrm{pH}=2.5$
c) Cel-g-AA, $\mathrm{pH}=5$
d) Cel-g-AA, $\mathrm{pH}=6$
e) Cel-g-AA, $\mathrm{pH}=7$

The surface morphology of the cellulose fiber grafted with acrylic acid at different graft percentages was examined using scanning electronic microscopy (SEM) according to the micrograph sequence presented in Figure 3. Small deposits on the irregular fiber grow around it, covering it completely are observed at $\mathrm{pH} 5$ in Figure 3. At pH 6, a greater quantity of deposited material is observed. The maximum graft percentage occurs at $\mathrm{pH} 7$.
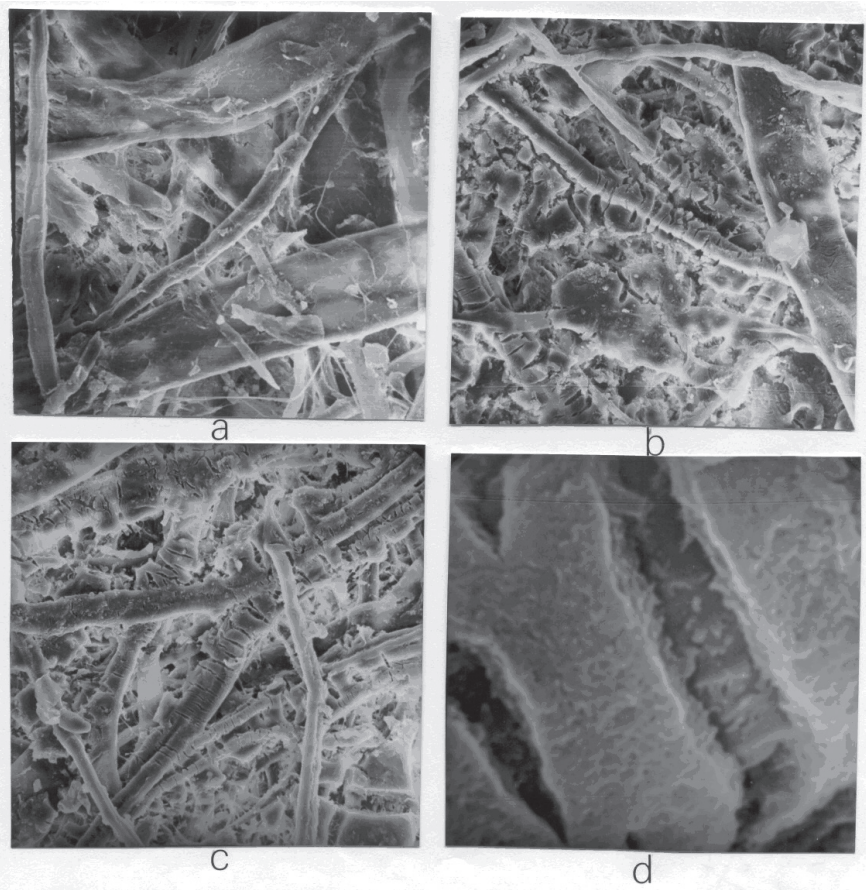

Figure 3: SEM Micrographs a) Cel-g-AA; pH $5(400 \mathrm{X})$ b) Cel-g-AA, pH $6(400$ X) c) Cel-g-AA, pH 7 (400 X) d) Cel-g-AA, pH 7 (16000 X)

It is important to observe that as the reaction time increases, new bands appear in the IR spectrum that could indicate a polymer degradation process (figure 4). The increase of the band $2963 \mathrm{~cm}-1$ signals a vibration of the C-H stretching of new methylene groups in the polymeric unit. The band at 1260 $\mathrm{cm}-1$ corresponds to a vibration of $\mathrm{C}-\mathrm{O}$ stretching and the $-\mathrm{CH}_{2}$ - rocking vibration at $803 \mathrm{~cm} 1$ corresponds to the methylene groups. These absorption bands are very intense at 17 hours of reaction .

Santa Fe cellulose grafted with the system AA - Mn(VII)/ $\mathrm{H} \mathrm{C} \mathrm{O}-\mathrm{Mn}^{2+}$ and Microcrystalline cellulose grafted with AA and Ce (IV), $\mathrm{Mn}\left(\mathrm{VII}^{2}\right) / \mathrm{H}_{2} \mathrm{C}_{2} \mathrm{O}_{4}-$ $\mathrm{Cu}^{2+}$ and Fenton, presents similar spectral data (Figure 4 and Figure 5). 


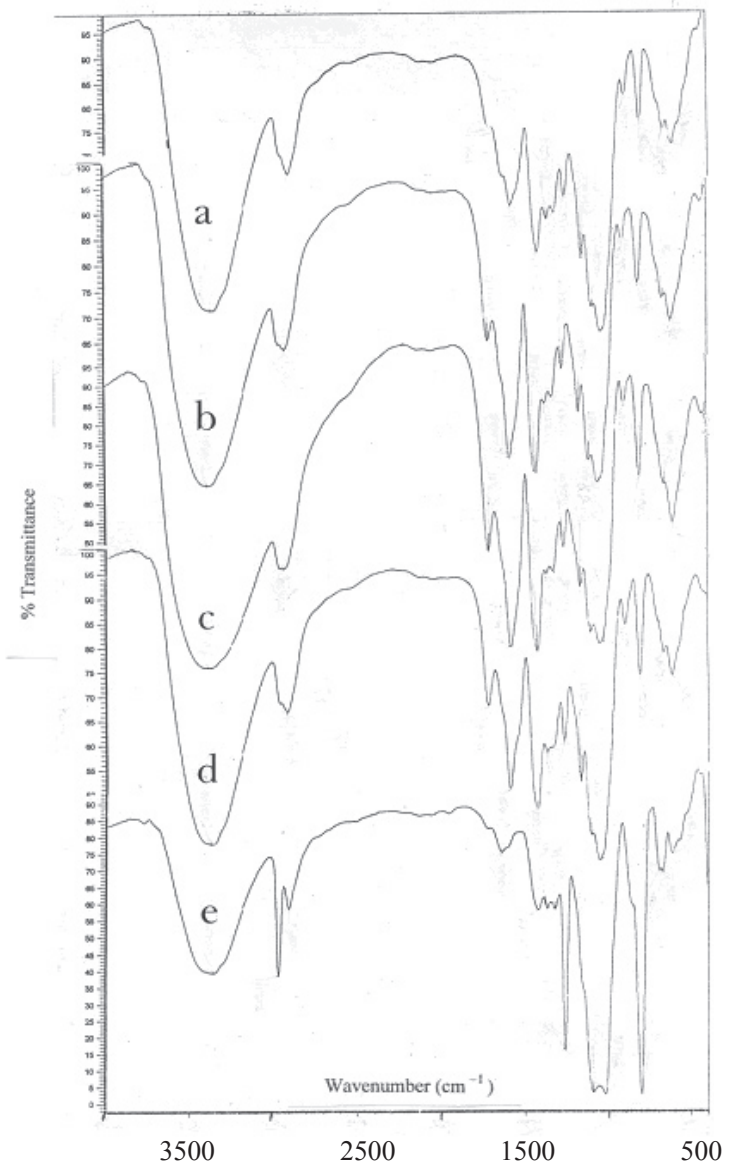

Figure 4: FTIR spectrum for Santa Fe Cellulose grafted with Acrylic Acid with $\mathrm{KMnO}_{4} / \mathrm{H}_{2} \mathrm{C}_{2} \mathrm{O}_{4}$ initiator and $\mathrm{Mn}^{2+}$ co-initiator at different polymerization times: a) 1 hour, b) 2 hours, c) 3 hours, d) 4 hours and e) 17 hours.

Another significant aspect in this reaction is the absence of the carboxylate band at $1580 \mathrm{~cm}-1$, which demonstrates the low availability to form a metallic complex with this group.

he addition of $\mathrm{Cu}^{2+}$ or $\mathrm{Mn}^{2+}$ catalyst as sulphates would raise both, the initial rate and maximum conversion. A disproportionation reantion occurs between $\mathrm{Mn}^{2+}$ and $\mathrm{Mn}^{4+}$ ions, producing the highly active $\mathrm{Mn}^{3+}$ ions in the system at a rapid rate. The $\mathrm{Mn}^{3+}$ reacts rapidly with the organic substrate, oxalic acid, prodining free radicals. These radicals propagate the polymerization at a comparatively faster rate.

To determine the efficacy of the different metals used as radical initiators, the graft of acrylic acid in microcrystalline cellulose with the ions Ce (IV), $\mathrm{Mn}$ (VII) and Fenton were studied at 17 hours.(Figure 5).

The principal band at $1715 \mathrm{~cm}^{-1}$, characteristic of carboxylic groups is diminished after 17 hours of reaction with 3 different initiators: Ce(IV), $\mathrm{Mn}(\mathrm{VII})$ and Fenton. A broad

band with two peaks near 1098 and $1025 \mathrm{~cm}^{-1}$, due to the structure stretching of C-COOH, is increased. Methylene rocking at $803 \mathrm{~cm}^{-1}$, increases with the time too. The polymer degradation is supported by this data.

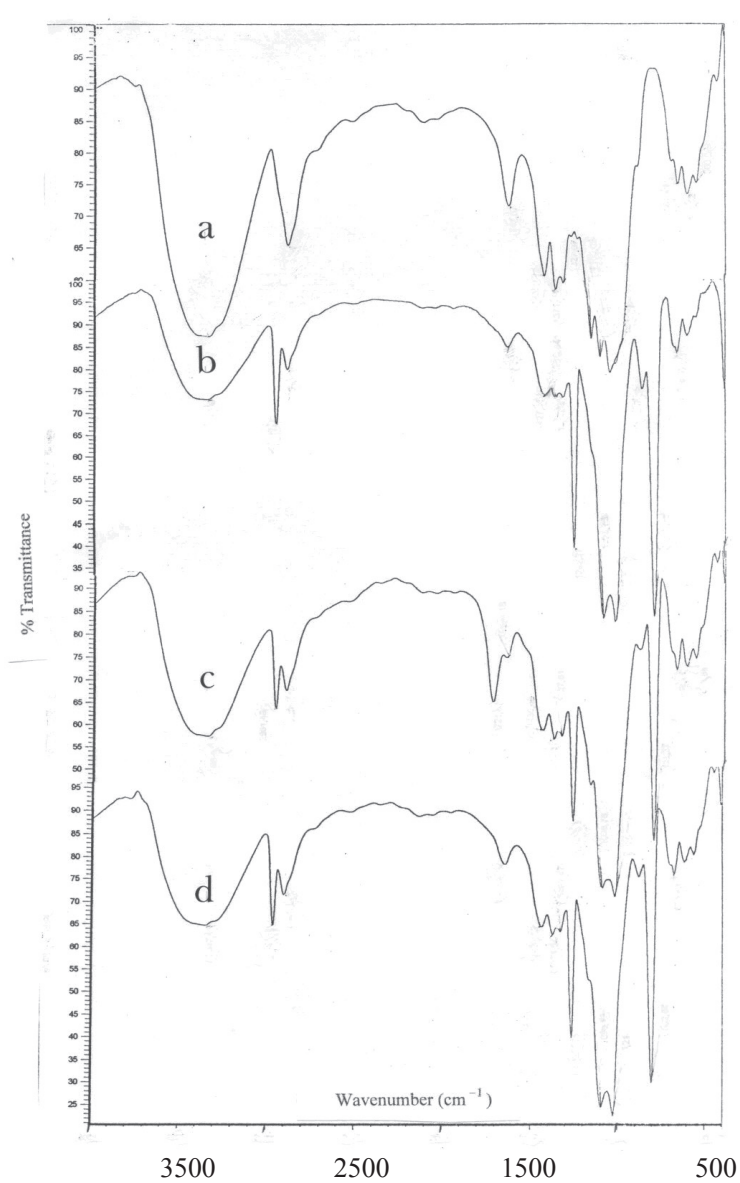

Figure 5: FTIR spectrum for Microcrystalline Cellulose (avicel) grafted with Acrylic acid and different initiators at 17 hours and $70^{\circ} \mathrm{C}$. a) Pure Avicel, b) Avicel with $\mathrm{KMnO}_{4} / \mathrm{H}_{2} \mathrm{C}_{2} \mathrm{O}_{4}-\mathrm{Cu}^{2+}$ and c)Avicel with $\mathrm{Ce}$ (IV) / $\mathrm{HNO}_{3}$, d) Avicel with Fenton

The micrographs in Figure 6 present cellulose materials whose surface was attacked and clearly degraded.

The cellulose material micrographs are presented in Figure 6. It shows the $\mathrm{Fe}^{2+}$ and $\mathrm{Mn}^{7+}$ action on grafted Avicel at $70^{\circ} \mathrm{C}$ and 17 hours as reaction time. The initial crystallinity changes with the time and temperature. Grafted Avicel becoming an amourphous and smooth material with Fenton and $\mathrm{KMnO}_{4}$ reagents at large time and temperature. 

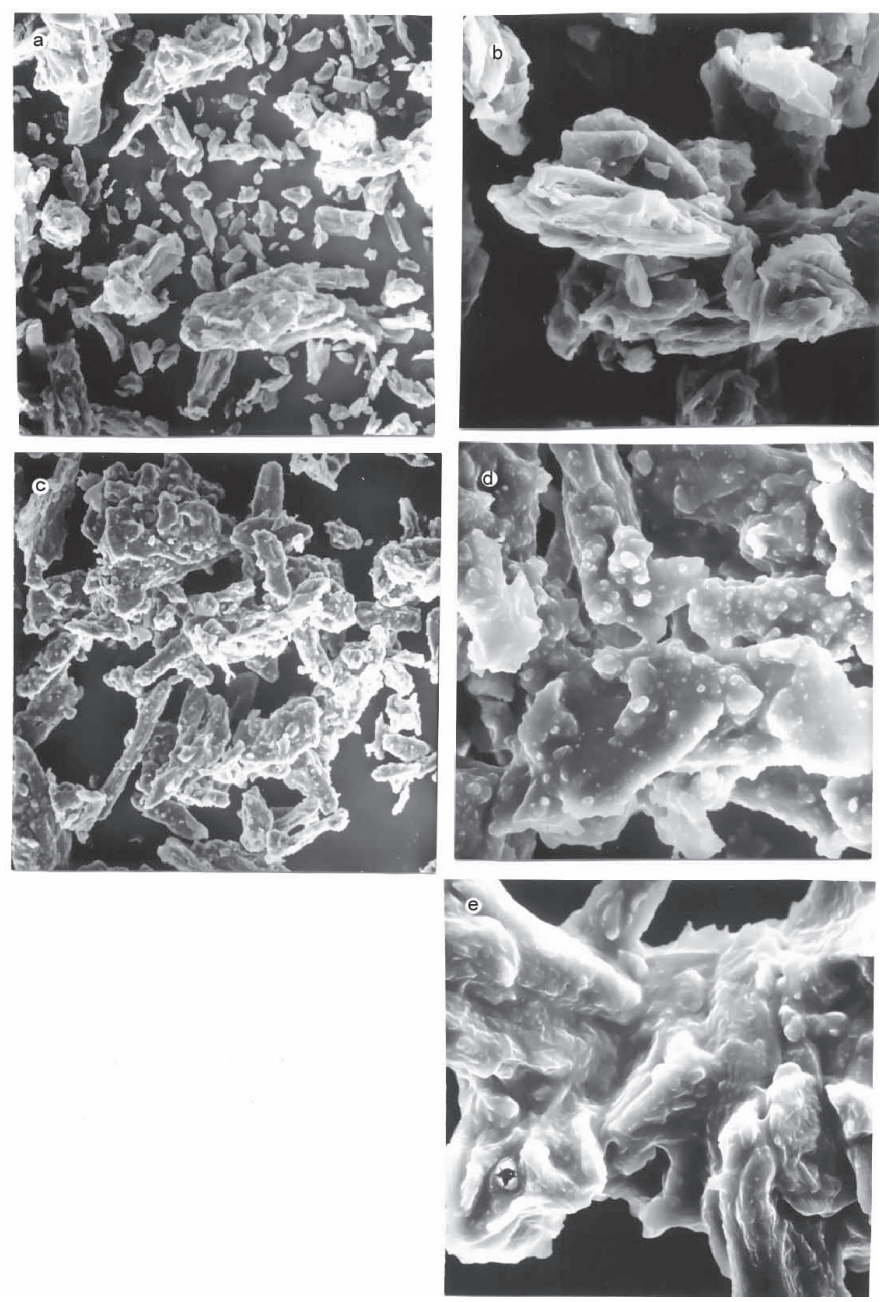

Figure 6: SEM micrographs a) Avicel (100X) b) Avicel (800 X) c) Avicel g-AA-Fenton (500X) d) Avicel -g-AAFenton (1000X) e) Avicel-g-AA$\mathrm{KmnO}_{4}(1000 \mathrm{X})$.

This figure shous the action of $\mathrm{Fe}^{2+}$ and $\mathrm{Mn}^{7+}$ on grafting cellulose.

The secondary pulp is modified by Fenton's reactive at different times and reaction temperatures (Figure 7).

The secondary cellulose is modified by Fenton during 3 and 17 hours, at 50, 60 and $70^{\circ} \mathrm{C}$ as reaction temperature. The wide band at $3420 \mathrm{~cm}^{-1}$, characteristic of hydroxyl group is very diminished (Figure 7b). Other important bands at $1260,1094,1025,803 \mathrm{~cm}^{-1}$ are shown too. They increase in absorption as the time increases. These features are evidence for the microcrystalline cellulose degradation with different times and temperatures reaction.
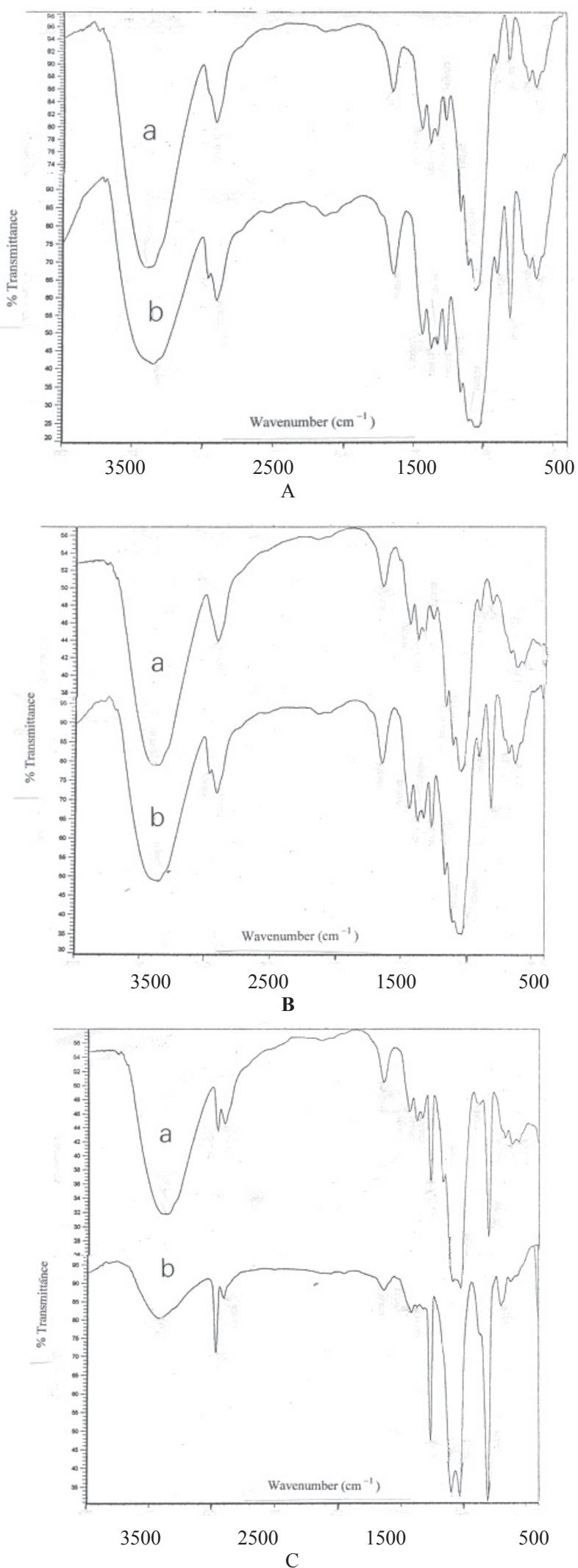

Figure 7: FTIR spectrum for secondary pulp with Fenton at different reaction temperatures and times: $\mathrm{A}: 50^{\circ} \mathrm{C}, \mathrm{B}: 60^{\circ} \mathrm{C}, \mathrm{C}: 70^{\circ} \mathrm{C}$ and a) 3 hours b) 17 hours. 
The cellulose material of smooth fiber was modified with the reaction time. It becoming an agglutinated and amorphous material with granulated surfaces, indicating fiber degradation (Figure 8).
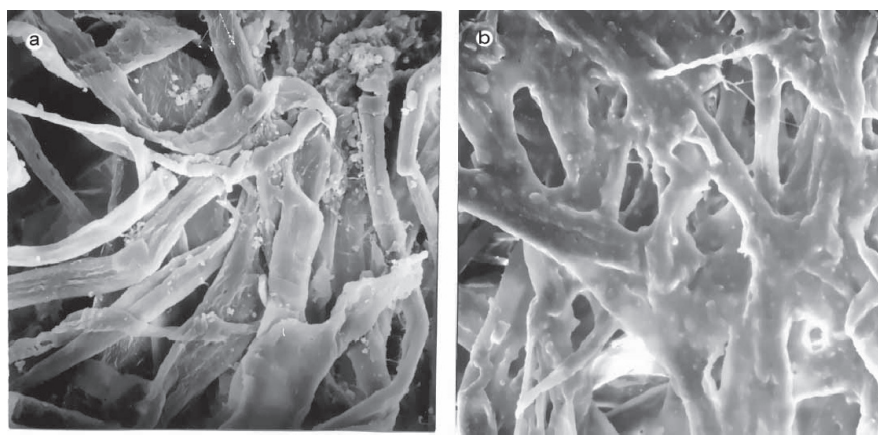

Figure 8: SEM micrographs a) secondary pulp (500X) b) secondary pulp with Fenton at $60^{\circ} \mathrm{C}$ and 17 hours of reaction. (4000X).

It can been proposed that in acidic medium the oxidation of primary hydroxyl in the C-6 conduces to the formation of the carboxylic acid. Then the iron complex is formed and finally the decarbaxylation is produced (Diagram I).

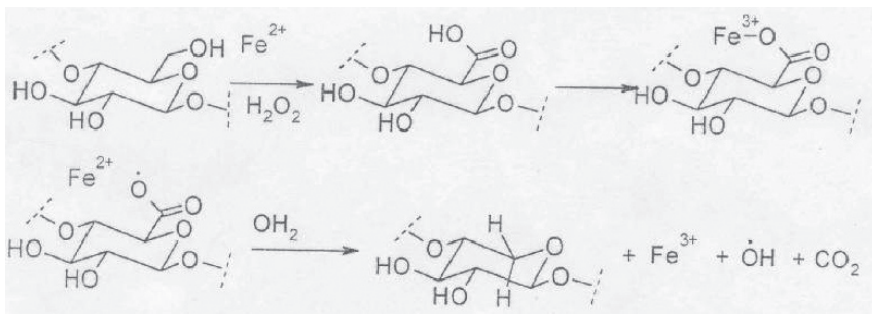

Diagram I

\section{CONCLUSIONS}

The radical grafting reaction variables such as $\mathrm{pH}$, initiator system, cellulose nature and reaction time, were studied. By physical and chemical modifications the degradation polymer was investigated.

- The grafting by Fenton-system of AA onto cellulose reaching a maximum at $\mathrm{pH} 7,90 \%$, and then the percentage is reduced to $30 \%$. FTIR spectrums and SEM micrographs evidence these changes. The carbonyl group at $1718 \mathrm{~cm}^{-1}$ and small new deposits covering the irregular fibers are presented.

- Santa Fe cellulose is grafted with AA and system Mn(VII) - Mn(II) as co-initiator, at 17 hours as reaction time. This cellulose is degraded at $70^{\circ} \mathrm{C}$ and 17 hours, as time reaction. This is corroborated by FTIR spectrums.

- Avicel grafted with AA and three different initiator systems: $\mathrm{Ce}(\mathrm{IV}) /$ $\mathrm{HNO}_{3}, \mathrm{KMnO}_{4} / \mathrm{H}_{2} \mathrm{C}_{2} \mathrm{O}_{4}-\mathrm{Cu}^{2+}$, and $\left.\mathrm{Fe}(\mathrm{II}) / \mathrm{H}_{2} \mathrm{O}_{2}\right)$; at $70^{\circ} \mathrm{C}$ and 17 hours is degraded. FTIR spectrums and SEM micrographs evidence these changes . The principal band at $1715 \mathrm{~cm}^{-1}$, carboxylate group, is diminished and grafted Avicel becoming an amourphous material.

- For grafting AA onto cellulose fiber, Ce(IV) is the best initiator. It was observed a minor monomer incorporation with Fenton and Mn(VII)/ $\mathrm{Cu}$ (II)initiator. By analysis of the band intensity of carboxyl group at $1715 \mathrm{~cm}$ ${ }^{1}$ in the FTIR spectra, this was performed qualitatively

- Secondary pulp in reaction with Fenton reagent at $70^{\circ} \mathrm{C}$ and 17 hours is degraded. FTIR and SEM confirm the new amorphous material

\section{ACKNOWLEDGEMENTS}

Thanks are given to the Proyect $N^{\circ} 020404$ 3/R , Research Direction, University of BíoBío of Concepción.

\section{BIBLIOGRAPHY}

1. Yoshikimi Uyama, Koichi Kato; Yoshito Ikada Advances in Polymer Sci., 137, 1-39, (1998)

2. John Z. Lu, Qinglin Wut, Harold S. McNabb, Jr., Wood and Fiber Science, 32 (1), 88-104, (2000)
3. Gehui Wang, Zhanqian Song, Zhifeng Lin, Liansheng Wang, Journal of Applied Polymer Science, 83, 2390-2396, (2002)

4. Pingyu Yang and Serge Kokot, Journal of Applied Polymer Science, 60, 1137-1148, (1996)

5. Olfat Mansour; Ahmed Nagaty., Progress Polymer Science, 11, 91165.,(1985)

6. Tsujiyama S., Miyamori A., Thermochim Acta, 351, 177-181, (2000)

7. Pronoy K., Chafferjee and Robert Schwenker Jr., Tappi, 55, 511-515, (1972)

8. N. Grassie, Journal of Applied Polymer Science. Appiled Polymer Symposium., 35, 105-121, (1979)

9. A. Enoki, H. Tamaka and G. Fuse, Wood Science and Technology, 23, $1-12,(1989)$

10. K. Garves, Holzforschung, , 51, 6, 526-530 (1997).

11. Matija Strlic, Jana Kolar, Majda Kigon and Boris Pilhar, Journal of Chromatography A., , 805, 93-99 (1998).

12. A D.A Berlin and V. N. Kislenko Prog.Polym.Sci.,17, 765-825 (1992)

13. A.S.Sarac, Prog. Polym.Sci. , 24, 1149-1204 (1999)

14. V.A. Molotrov, V.I. Kurlyankina and S.I. Klenin, Vysokomolek.Soedin, 414, 2478 ( 1972)

15. S.H.O., Egboh and B.Jinadu, Angew.Macromolec.Chem.,163, 93(1988)

16 .Kiwi and C.Pulgarin, Appl. Cat. Environ.,3, 335 (1994)

17 A.Safarzadeh-Amiri, J.R.Bolton and R.Cater, J.Adv.Oxidation Technol.,1,18 (1996)

18 V.Nadtochenko and J.Kiwi, J. Chem. Soc.,Faraday Trans., 93, 23732378 (1997)

19 Rowan, J.W.,F.H. Forziati and R.E.Reeves, J.Am.Chem.Soc., 73, 4484(1951)

20 Lian C.Y.,Krimm and G.B.M.Sutherlad, J.Chem.Phys., 25,543, (1956)

21 H.G.Higgins, C.M.Stewart and and K.J.Harrington, Journal of Polymer Science, 51, 59-84 (1961)

22 Marta Fernández García Sánchez-Chaves, Journal of applied Polymer Science, 102, 4238-4244 (2006)

23. Bowen Cheng,Xiaoming Jiao, Weimin Kang, Journal of Aplied polymer Science, 102, 4977(2006)

24. Watanabe M. H.Shirouchi H. and Hosaka T. (Assignal to Toyo Rayon Co.Ltda ) Graft Copolymers,Japan 17634,161 September 28 (1961)

25. El-Rafie, M.H.Waly A.I.and Hebeish A.,J.Polym.Sci.,Polym.Chem. Edn.14, 2903-2909 (1976)

26. Kanby B., Symp.Cellulose Pulp. Text. Div. Am. Chem. Soc. 1977. Pub.(1978),171-195;Chem.Abstr. 91, 39310 j (1979)

27. Gauri S., Misra and Josep J. Rebello,Die Makromolekulare Chemie 175, 3117-3131 (1974)

28. Gauri S.,Misra and Joseph J.Rebello, Die Macromolekulare Chemie, $176,2203-2223(1975)$

29. A.Gopalan, P,Venurana Lingam, S.P.Manuckam, K.Venkatarao, Eur. Polym. J., 18, 531-534 (1982)

30. K.C.Gupta, M.Varma and K.Behari, Macromolecules, 19, 548-551 (1986)

31. T.Balakrisnam and S. Subbu, Journal of Polymer Science, PartA;,Polymer Chemistry 24, 2271-2278 (1986)

32. K.C. Gupta and Sujata Sahoo Biomacromolecules 2,239-247 (2001)

33. Bazuaye A., Okiemen, F.E., Sai, O.B.Acta Polymer, 40, 126 (1989)

34. D.J.McDowall,B.S.Gupta and V.Stannet, Am.Chem.Soc.Symp.Ser., 157,45 (1982)

35. S.B.Vitta, E.P. Stahel and V.T. Stannett,J.Macromol. Sci. Chem., A22 (57) $579-590$ (1985)

36. R.Catalán S.,A.Neira J.,R.Melo, B.Rivas. a) Bol.Soc. Chil.Quím., 44,505,(1999). b) Bol. Soc. Chil. Quím.45,321(2000), c) Bol.Soc.Chil. Quim, 47,039 (2002)

37. A.Burke, E. Yilmaz, N.Hasirci, O.Yilmaz,J.Appl. Polym. Science, 84, 1185-1192 (2002) 